\title{
Semiotics of Eternalization. English General Survey and Summary
}

The aim of this general survey and summary ${ }^{1}$ is to bring the present monograph closer to an anglophone readership. Thus, the focus will be on those aspects and results of this study that go beyond the examined German sources. These aspects are first and foremost theoretical and historical in nature. The following text consists of an abridged version of the German summary, framed by a few translated excerpts from the introduction and the outlook. Complementary footnotes as well as longer definitions of concepts are omitted; see for reference the respective chapters in German. The same is the case for the interpretations of individual literary texts.

\section{Point of Departure}

The aim of the present monograph is to engage the notion present in occidental cultural space, from the point of view of literary studies and semiotics, that characters (i.e. written signs) are able to eternalize thoughts, things, or persons and their deeds, that is to record them for all time. Therefore, our point of departure is a paradoxical one: On the one hand, we find this notion. On the other hand, characters are extremely ephemeral with regard to semiotics: During the course of reading, they will never be able to evoke the exact same signified twice, and will, as soon as they have been read, have been nothing but (for example) mere black ink on white paper. On the level of the physical and biological, it should also be noted that neither the readership nor the material dimension of writing and writing surfaces exist outside of time, but instead are subject to death and decay.

The present work takes on the intellectually productive irritation inherent in every paradox, especially this one. This leads to a first conceptual distinction necessary to avoid later confusion: In the following, rather than address the "notion that characters are able to eternalize thoughts, things, or persons and their deeds", we will instead use the more precise terms eternity-assertion toward characters and eternity-attribution of characters.

1 Editor and translator of the English general survey and summary: Andreas Inderwildi. 
Eternity-assertion toward characters describes all those text passages which, despite the ephemerality mentioned above, assert the power of characters to eternalize thoughts, things, or persons and their deeds. This assertion can be either implicit or explicit, and the distinction is not always a clear one. Eternity-attribution of characters on the other hand describes those attempts which, in a given written utterance, utilize intralinguistic operations in order to 'disable' the semiotic ephemerality of characters and thus record for all time the signifieds of the respective utterance. Thus, in the case of eternityattribution, the above-mentioned ephemerality of characters isn't 'denied' or ignored (as is the case for eternity-assertion), but instead attempts to counteract it as far as possible by engaging with this ephemerality - which, in some cases, is paradoxically accomplished by exploiting ephemerality itself. $^{2}$

The present study intentionally focuses on a time period in which a discursive and historical intensification of the thematization of eternity, ephemerality and (industrial) reproducibility, as well as questions of conditions and possibilities of human understanding, have already been determined by previous research. This study seeks to answer two guiding questions:

1. Which intralinguistic operations can be observed in the attempt to 'disable' the semiotic ephemerality of characters in order to record a given written utterance's signifieds for all time and thus to eternalize thoughts, things, or persons and their deeds by means of characters?

The aim of answering this question lies in developing a typology of such intralinguistic operations of the eternity-attribution of characters. This study does not lay claim to presenting a complete and conclusive typology. However, it does seek to classify and discuss those operations which have seen the most frequent use (at least in the chosen period of around 1800). In order to prevent potential misunderstandings, it is necessary to emphasize that this study's aim is not to search for the 'philosopher's stone', but instead to establish a typology of mere attempts to 'disable' as far as possible the ultimately uncircumventable semiotic ephemerality of characters.

2 At least in the case of more ambitious authors, we can frequently also find passages with eternity-attributions in close proximity to passages with eternity-assertions. In the course of this study's main part, this can be observed again and again. 
2. How can we contextualize, from the point of view of literary studies and intellectual history, intralinguistic operations of the eternity-attribution of characters in the period from 1755 to 1821 ?

The issue at hand is to observe the kind of correlation existing between intralinguistic ${ }^{3}$ operations of the eternity-attribution of characters on the one hand and contemporary intellectual and literary historical contexts and co-texts on the other; and furthermore to determine if a certain accentuated occurrence of individual instances of such operations can be observed, and if yes, for what reasons.

The process of answering these guiding questions mainly takes place through engaging with exemplary literary as well as theoretical texts of the German language area in the period between 1755 and 1821. Even though the close readings of the individual texts may be inspired by deconstructionist methods, they still remain faithful to the fundamentally hermeneutic approach of the present study, which does not refrain from critically questioning deconstructionist eternity-assertions. If the present study was not dedicated to an approach decidedly defined by close readings, it would run the severe risk of engaging in mere eternity-assertion toward characters itself. The reason for focusing mainly on literary texts is that literature is the 'space' in which the possibilities and limits of language and characters are experimented with most intensely - especially in a period in which modern philological disciplines were still nascent.

\section{A Typology of Operations of the Eternity-Attribution of Characters}

The following chapter brings together and elaborates on the literarysemiological findings of the study and processes the resulting typology for operations of the eternity-attribution of characters in the form of the following table.

3 It has now been noted several times that the examined operations are intralinguistic. In the following, the adjective 'intralinguistic' will be omitted for the sake of reader-friendliness. 
Basic operations in the service of the eternity-attribution of characters
A) Endless Actualization
B) Autonomous Performative
Production
C) Reflexivity
(autonomous and/or endless)

Basic and sub-operations in the service of the eternity-attribution of characters
A) Endless Actualization
B) Autonomous Performative
C) Reflexivity
Production
- Endless Reading
- Poetic Performativity
- Autoreflexivity
(auton. and/or endl.)
- Endless Falling Silent
- Poetology
(auton. and/or endl.)

The respective basic and sub-operations attempt to achieve

$\begin{array}{ccc}\text { - interminable reading } & \begin{array}{c}\text { autonomy from temporal } \\ \text { changes in semantics and } \\ \text { context }\end{array} & \begin{array}{c}\text { autonomy from } \\ \text { temporal changes in } \\ \text { semantics and context } \\ \text { and/or }\end{array} \\ & - \text { interminable reading }\end{array}$

Basic operation 'endless actualization': Attempts to bring readers to read and re-read the respective characters or texts an infinite amount of times, for example by means of narrative-compositional circular structures, complex and decisively placed intra- and intertextual references, the confusion of narrative frames (sub-operation: 'endless reading') or the purposeful breaking or interruption of a text in order to render its semiotic ephemerality aesthetically utilizable as well as to provoke continued thinking about and writing in 'continuation' of the original text (sub-operation: 'endless falling silent').

Basic operation 'autonomous performative production': Attempts to make each reading create that which the text refers to in order to imbue it with as much autonomy as possible, for example by interspersing the mentioning of an echo with repetitive figures to such a degree that an echo effect is created through the very act of reading the text. 
Basic operation 'reflexivity': Attempts to either imbue a text with as much autonomy as possible by reference to itself (sub-operation: 'autoreflexivity') or its own conditions of possibility (sub-operation: 'poetology') or to 'force' readers to reproduce the potentially endless movement inherent in every self-reference, for example by describing how a novel's characters discover the 'same' novel of which they are a part and proceed to read about themselves. ${ }^{4}$

Due to the restrictions on the levels of semiosis already mentioned in "point of departure", the biological constitution of humans as well as the material dimension of writing, an interminable reading is ultimately as out of reach as an absolute autonomy from time and context. An eternalization by means of characters in a true and absolute sense is impossible and must always remain a mere attempt. With this we reach a question that imposes itself again and again throughout the study's main part: What kind of effects do the respective operations actually achieve in the course of the reading of texts equipped with those operations?

First, we might suggest the answer that at least some of the operations under discussion, especially the basic operation 'endless actualization', would lead to a potentially endless iteration of characters. This, however, results in two problems: On the one hand, mere iteration turns out to be too vague a term to be of use, since a second reading of, for example, Lebens-Ansichten des Katers Murr is not simply a repetition of the first reading, but will, since it includes the first reading, have been a different one. On the other hand, every character has the potential to be repeated an infinite amount of times; for this, operations of eternity-attribution are not (yet) necessary, even though certain operations try to realize this potential before all else. These problems, however, can be met. For a precise distinction between that which operations of the eternityattribution of characters attempt to achieve and that which is achieved in the course of those attempts, Jacques Derrida's concept of iterability (French 'itérabilité') proves itself to be exceedingly helpful.

According to Derrida, the conditions of possibility of each sign, and as a result also of each character, is its potential to be repeated an infinite amount of times, or more precisely its iterability, in the course of which a sign will have been actualized again and again (never, however, the exact same twice). Certain operations of the eternity-attribution of characters attempt to expedite this potentially endless repeatability by trying to force readers to not only use that potential for the respective reading, but instead to exhaust it in its endlessness. Text passages that contain the other operations, by virtue of being

4 The definitions as seen here have been abbreviated for the sake of an improved understanding of the summary; the full definitions can be found at the beginnings of the respective chapters of the German language main part. 
structures of signs and characters, may also have iterability as their condition of possibility, but do not attempt to exhaust their infinite potential. This can be expressed more precisely through the following two findings:

1) Those operations which lead to a forced iterability attempt to substitute eternity with endlessness, or in other words to replace timelessness with the most radical emphasis on temporality possible. This is true not only for the operation 'endless reading', but also for the operation 'endless falling silent', which, through diametrically opposed means, namely a radical use of characters' semiotic ephemerality, in a sense pursues the same goal as the former. This also holds true for the basic operation 'reflexivity' in all those instances in which it not only pursues a text's autonomous self-thematization, but at the same time also fosters an endless mirroring movement.

2) The first finding does not apply to those operations which lead to an iterability of potentially autonomous performative production, since they do not strive toward a substitution of eternity with endlessness, but rather - in the context of the above-mentioned semiotic, biological and physical restrictions toward an autonomy from temporal changes in semantics and context of that which has been put into writing. The latter is also true for the basic operation 'reflexivity', as long as it does not at the same time lead to, or (more precisely) force, an endless mirroring movement. The basic operations 'autonomous performative production' and 'reflexivity', however, create potential autonomy in two different ways: The former through performatively creating that which the signs refer to, the latter through a respective passage's references both to itself as well as to its own conditions of possibility. In the course of this selfreferencing, the respective passage's iterability itself may be negotiated, as has been shown in the chapters discussing Heinrich von Ofterdingen, Nänie as well as the fable Der Phönix.

Uwe Wirth writes, concerning Derrida's concept of iterability, that the iterability of signs is grounded in their power of breaking with context. ${ }^{5}$ Building on Wirth's (and Derrida's) statements, the findings discussed above may be summarized as follows: The operations of the eternity-attribution of characters attempt (of course with varying emphasis) to exhaust the two central constituents of iterability: potential endlessness on the one hand, and potential autonomy from time and context on the other. This, too, can be illustrated via tables:

5 Cf. Wirth 2oo8, pp. 61-62. 
Basic operations in the service of the eternity-attribution of characters
A) Endless Actualization
B) Autonomous Performative
C) Reflexivity Production
- Endless Reading
- Poetic Performativity
- Autoreflexivity
(auton. and/or endl.)
- Endless Falling Silent
- Poetology
(auton. and/or endl.)

The respective basic and sub-operations result in

\begin{tabular}{|c|c|c|}
\hline - forced iterability & $\begin{array}{l}\text { - iterability of } \\
\text { potentially autonomous } \\
\text { performative production }\end{array}$ & $\begin{array}{l}\text { - iterability of } \\
\text { potentially autonomous } \\
\text { reflexivity } \\
\quad \text { and/or } \\
\text { - forced iterability }\end{array}$ \\
\hline \multicolumn{3}{|c|}{ a combination of A) and B) or A) and C) results in } \\
\hline & $\begin{array}{l}\text { - forced iterability of } \\
\text { potentially autonomous } \\
\text { performative production }\end{array}$ & $\begin{array}{l}\text { - forced iterability of } \\
\text { potentially autonomous } \\
\text { reflexivity } \\
\quad \text { and/or } \\
\text { - (forced iterability })^{2}\end{array}$ \\
\hline
\end{tabular}

Finally, another noteworthy combination - this time on the level of two suboperations - seems to constitute the fragmentary: It could be said that the fragmentary is a radical manifestation of the sub-operation 'endless falling silent', which, precisely because of its radicality, also triggers a potentially endless movement which continues the fragmentary texts and which ultimately overlaps with the sub-operation 'endless reading'. The same holds true in the opposite direction for the sub-operation 'endless reading', which in its most extreme manifestation tends toward the fragmentary. Or to put it somewhat more simply: The fragmentary in a sense makes possible a combination of the complementary sub-operations 'endless falling silent' and 'endless reading', 
and as a result may be the most effective feasible manifestation of the basic operation 'endless actualization'.

\section{A 'Localization' of the Operations in the Historical Context of the 18th and early 19th Century}

The most important observations of the main part with regard to intellectual and literary history will now be placed in relation to the two central, abovementioned findings regarding typology:

Finding 1) has, in the case of the operations in question and on a purely semiotic level (and thus fundamentally independent from language, writing and period, as has been shown in the introduction and main part's references to ancient Egypt and Greece), recorded a 'compensation' of unreachable eternity through endlessness. This finding and the results of the historicalcontextualizing chapter can now be merged to create the following thesis:

The semiotic 'compensation' of eternity through endlessness finds, to a large extent, a correspondence on the level of intellectual and literary history, which leads to an accentuated occurrence of the operations of the eternity-attribution of characters in question. This is especially true in the case of the operations 'endless reading' and 'endless falling silent', as well as the basic operation 'reflexivity' in those instances in which it primarily aims for an interminable reading.

The intellectual historical background of this correspondence are developments whose occurrence is intertwined and, in the course of the Enlightenment, intensified. This can be seen, for example, in the constitution of the 'modern' individual, the 'softening' of the mimetic imperative through a dynamization of nature, the elevation of creative imagination and its aestheticization as well as the increasing historical relativization of 'authorities' or their works, be it in the realm of religion, science or literature. All of this leads to or is paralleled by a process of secularization, in the course of which a 'compensation' of the 'loss' of Holy Scripture (as well as the religious promise of eternal life after death) can be observed through a sacralization of writing as such. The eternity of individuals' written works is not only asserted explicitly or implicitly in the continuation of millennia-old notions, but rather is pursued through an increasing intellectual effort with regard to eternity-assertion and -attribution. ${ }^{6}$ Eternity-assertion and -attribution, however, play their

6 It is highly noteworthy that Jan Assmann notes an 'explosion' of eternalization efforts during a 'similar' time of religious crisis in the Late Period of ancient Egypt. This led to a sophisticated combination of characters and procedures of architecture, ritual, pictorial representation 
part in further expediting secularization, which in turn leads to an increased sacralization of writing as such.

Thus, it becomes clear that in this interplay itself an endless movement is inscribed that ultimately persists into the present and gains a new-found momentum in today's 'digital revolution. ${ }^{7}$ The 'aesthetics of genius' emerging in the early 1770s (whose lasting effect can still be felt today in science, art, copyright etc.) especially play a defining part in this interplay: In it is carried out to its most explicit and radical degree not only the transfer of the divine attribute of creativity to the human, but also the transfer of the divine attribute of God's eternity to the individual, and in turn from individuals to their work. Even though this transfer of the creative has found broad scholarly agreement some time ago, the present study has been able to reveal the close entanglement between this transfer and the transfer of the attribute of eternity. An individual which seeks to permanently ensure for itself the status of genius is subject to a potentially endless pressure of creation. Or put differently: A genius must, in order to remain as such, either create something eternal or create eternally.

With regard to literary history, the above-mentioned interplay between this historical relativization and, on the one hand, the 'loss' of the religious promise of eternity and, on the other hand, the written 'compensation' of the same, contributes substantially to known aesthetic configurations, experiments and disputes and through these gathers further momentum - as has already been hinted at by referencing the 'aesthetics of genius'. From the middle of the $1750 \mathrm{OS}$ onward, Gotthold Ephraim Lessing played a defining role in this. Lessing's paradigm change within the contemporary genre of the 'Trauerspiel' (or tragedy) not only corresponded to a prioritization of the duration of compassion toward the terrible moment, but also lead to a dissolution of the 'trinity' of beginning, middle and end postulated by Aristotle; a dissolution which occurs in the sense that, in Lessing's bourgeois 'Trauerspiel', the end is turned into an ongoing ending and thus becomes the middle. The potency of this shift of the end to a 'middle' can hardly be overstated, since not only did it attempt a transformation of the exemplary genre of the tragedy, but was also instrumental in the 'dissolution' of the (seeming) 'unity' of works of every genre. Together with the utilization of the fragmentary form that occurred only slightly later ${ }^{8}$ (through Hamann, Herder and later again especially through

and sympathetic analogy in order to reach - in the terminology of the present study - the most efficient eternity-attribution of the mediated contents (cf. J. Assmann 1991, pp. 73-74).

7 See also the outlook further below.

8 Cf. chapter II.3.4. 
Lessing's 'Reimarus fragments') this shift lead, through Goethe, Jean Paul and the early Romantics among others, to an aesthetic of the fragment in the following decades, which, sixty-five years after Miss Sara Sampson, finally reaches another apex with E. T. A. Hoffmann's Lebens-Ansichten des Katers Murr. In Hoffmann's 'twin novel', the end does not only become the middle, but also the beginning. The attempted 'compensation' of eternity through endlessness is carried out both on the micro level - see for example the observations regarding the use of dashes, breaks and paragraphs in Lessing, Jean Paul or E. T. A. Hoffmann among others - as well as on the macro level, for example by means of circular structures, framing narratives which are left open in the 'end', or framing prefaces, postfaces and authorial or editorial fictions, which develop their own displacing dynamics.

In continuation of Uwe Wirth's research ${ }^{9}$, it also becomes clear with regard to the case of the 'editor's function' and especially of editorial fictions just how much they serve as 'guarantees' of the 'eternity' of the work published 'by them' and of its author. The eternity-attribution of characters, then, is a substantial, if not defining constituent not only of the fictional editor, but also of the genesis of modern authorship, which in turn again contribute to the eternity-attribution of characters. ${ }^{10}$

On the semiological level, finding 2) assigned the remaining operations to a second group, since they do not lead to a forced iterability or strive toward endlessness, but instead aim for a potential autonomy of writing from temporal changes of semantics and of the contexts of communication as well as extralinguistics.

This group of operations of the eternity-attribution of characters aiming for autonomy also displays strong correlations on the level of cultural and literary history in the examined time period, which in this case also leads to an accentuated occurrence of the operations in question. These are especially the basic operation 'autonomous performative production' and the basic operation 'reflexivity' in those cases in which it primarily aims for autonomy.

For this correlation, the most significant background with regard to intellectual history and the history of philosophy is the fact that - so the thesis of the corresponding main part's chapter - the 'Reflexions-Philosophie' (philosophy of reflection) beginning with Descartes attempts to win back the

9 Cf. especially Wirth 2008.

10 In this context it would be very interesting to engage more extensively with older forms of authorial and editorial fictions; for example by including texts from ancient Egypt, where fictional 'assertors' as well as framing narratives appear in the Papyrus 'Chester Beatty' (13th century BCE). These are texts dealing explicitly with eternalization (cf. J. Assmann 1991, p. 176, annotation 6). 
'loss' of eternity of the 'absolute' in which it itself has played a substantial part. In this attempt, it utilizes - since it is attempted through the medium of language - procedures which in the realm of literature correspond particularly to the operations of eternity-attribution 'auto-reflexivity' and 'poetology', or the basic operation 'reflexivity' respectively, and are thus much older than the corresponding developments in intellectual history.

Following the semiological findings one might specify: Just as the basic operations 'autonomous performative production' as well as 'reflexivity' (for the latter, however, it is not always the case) aim for an autonomy of that which has been put into writing, the 'Reflexions-Philosophie' builds on a procedure which constitutes an 'I' that thinks 'autonomously'. It has been observed in chapter IV.3.1. how potentially endless mirroring develops a dynamic of its own that is inherent in the 'Reflexions-Philosophie' and threatens to subvert it. In the case of the basic operation 'reflexivity' on the other hand, this dynamic may be emphasized, namely in those cases in which it aims for endlessness rather than autonomy. Or put differently:

One manifestation of the basic operation 'reflexivity' in a sense corresponds to that 'basic operation' which dwells within the 'Reflexions-Philosophie'; another manifestation, on the other hand, corresponds to that dynamic which is both inherent in the 'Reflexions-Philosophie' and a threat to its fundamental premise. The 'aim' of the basic operation 'autonomous performative production' in turn corresponds to that of the 'basic operation' of the 'Reflexions-Philosophie', but attempts to reach its aim in a different way.

Speaking about the latter, one might go as far as to say: Fichte, however, utilizes a procedure which is very similar to the basic operation 'autonomous performative production' by elevating the performative-creative - or put more boldly: the genius - and thus ultimately an aesthetic principle to the basic premise of his philosophical system through the I that constitutes itself. Likewise, a performative principle seems to be inherent in the dissolution of the mimetic imperative: If nature creates dynamically, the artistic, dynamic act of creation not only refers representatively to nature, but also simultaneously performs nature.

By bringing together the most important semiological and historical results, the main part of this study makes clear that different developments in intellectual history during the latter half of the 18th century display a structural similarity to the operations of the eternity-attribution of characters. This structural similarity is largely responsible for intensifying an interplay which, on the one hand, itself contains a potentially endless dynamic and, on the other hand, simultaneously blurs its own beginning. This interplay - and not 'just' those developments in intellectual history alone - is thus a main cause for 
experiments and configurations in literary history, such as the so-called aesthetics of the fragment, the genius, or autonomy. The latter corresponds to the fact that the semiotics of sensuality, which pose a problem to the emerging discipline of aesthetics at the tail end of the 18 th century ${ }^{11}$, join the millenniaold pursuit of the 'sign that shows itself'12 and the same hope of eternalization and eternity that has already been associated with the 'semiotics of the intelligible sign'.

With this, a new perspective in literary history on the period around 1800 that complements current research emerges: Aesthetic engagements between and within seemingly clearly distinguishable 'currents' such as 'Classicism' or 'Romanticism', as well as the 'isolated' position of individual authors such as Hölderlin and Jean Paul, may now also be traced back to distinct preferences of the 'currents' in question (or configurations in literary history respectively) as well as of the authors in question; various preferences regarding the question which operations should be used for eternity-attribution primarily and to which degree of radicalness. This is complemented by the research of the last few decades, which increasingly reveals the continuities and entanglements between configurations in literary history of that period from the 'Enlightenment' to 'Romanticism'.

\section{Outlook and Critical Reflection}

Of the many possible points of connection which the present monograph attempts to offer, one of each will be discussed for a handful of central topics, namely: a general semiotic typology, the history of cultural semiosis, and hermeneutics in connection with rhetoric.

It is striking that the present study's results on a semiotic, typological level finds common ground with Aleida Assmann's research. The operations 'endless falling silent' and 'poetic performativity', for example, display similarities with her concepts "Zeichenkraft" (power of signs) or "Zeichenlogiken" (logic of signs) respectively, which describe the "Entleerung (asemantische Zeichen)" (evacuation, asemantic signs) or "Vergegenwärtigung (magische Zeichen)" (realization, magic signs) respectively. ${ }^{13}$ Assmann follows Charles S. Peirce's semiotic classification of index, icon and symbol, but also adds her own, namely

\footnotetext{
11 Schneider 1998, p. 12.

12 Cf. ibid.

13 Cf. A. Assmann 2015, pp. 53-6o.
} 
performative, asemantic and magic signs. ${ }^{14}$ As has already been hinted at by Assmann herself, her typology carries great potential for literary studies, both with regard to analysis and heuristics. For this reason, it should conversely be clarified if and to what extent this study's typology, which specifically relates to eternity-attribution, may be merged into a general semiotic typology, especially in combination with Assmann's classification.

From a historical perspective, there is much evidence to suggest that the process of secularization has reached a new apex in the 'occidental' present of the early 21th century, while the sub-operation 'endless reading' seems to come to play an increasingly dominant role regardless of medium..$^{15}$ In the latter case, some examples are the hypertexts of the internet or, from the point of view of those who do the writing, wikis, while the potentially endless serial format ${ }^{16}$ has gained a dynamic of its own within the domains of books, cinema, TV and streaming. Many of these supposedly novel manifestations are ultimately digital translations or extensions of procedures that have already been observed for the period around 1800 in this study. Or to put the question more boldly: Is big data and the vision of the 'internet of things' ultimately exposed as nothing else but the most radical underpinning of all aspects of life through the sub-operation 'endless reading', nothing but yet another symbolic ${ }^{17}$ attempt at eternalization? ${ }^{18}$ All of this finally leads to a macro perspective on the history of cultural semiosis and the 'logic of signs' 19 on which it is based; a perspective which in turn is adopted by Assmann's research: To what extent and in what ways may shifts in a society's semiotic paradigm find expression in the 'manifestation' of operations of the eternity-attribution of characters? And could these operations also reveal themselves as 'strategies of duration' 20 on a macro level that transcends written texts?

With regard to hermeneutics, the following question imposes itself: What position within a hermeneutical theory adopt those text passages which contain an operation of the eternity-attribution of characters? We might put forward the following hypothesis:

\footnotetext{
14 Ibid. p. 53. Aleida Assmann uses 'performative' in the broader sense of 'instructions' (cf. chapter III.1), based on Austin's later writings. This explains why the narrower usage of the term 'performative' used in this study overlaps more with Assmann's 'magic signs'.

15 See also Brukamp 2011, pp. 77-92.

16 Cf. Fröhlich 2015.

17 Symbolic in the sense of 'zeichenhaft', not 'symbolisch'.

18 Cf. Krüger 2004, pp. 313-4 and p. 401.

19 A. Assmann 2015, p. 17.

20 Cf. A. Assmann 1999.
} 
Such text passages may well be the best potential 'points' of departure and/ or reference of any hermeneutical process, since they display, with regard to semiotics, the least dependence on time and context compared to other passages. ${ }^{21}$

If we further connect, with regard to hermeneutics and rhetoric, statements by Friedrich Schleiermacher as well as reflections by Emil Angehrn and Daniel Müller Nielaba ${ }^{22}$ with this study's findings, we additionally arrive at the following, complementary theses that warrant further examination:

1) Eternity serves as figural 'point of reference' of 'modern' understanding and through this attempts to ensure not eternity, but, at the 'least', a potential endlessness and, in doing this, 'propels' itself as an unending procedure. This, in turn, leads to an 'even greater' elusiveness of that figural 'point of reference,' and so on. However, if that point of reference was 'reached', eternally valid meaning would be understood through this procedure once and for all. This would also entail the end of this procedure and thus the end of 'modern understanding.'

2) With that, it also becomes apparent on a semiotic-rhetorical level that, conversely, eternity-attribution may be a defining constituent, perhaps not of figuration in general, but of rhetorical figures (and probably tropes). This would complement the first thesis with regard to the potentially endless movement, which is inherent in every figuration, but perhaps even with regard to (certain) procedures which pursue autonomy. The latter would be the case in those instances in which the achievement of poetic performativity can be observed as a defining aspect of the rhetorical figure in question. The present monograph has tried repeatedly to also address those eternityassertions and -attributions which it itself is subject to. And yet, in doing this, the author 'utilizes' both the basic operation 'reflexivity' and ultimately the operation 'poetic performativity' and thus performs another eternityattribution of his own work - and with this observation, we arrive at the next reflection and so on, ad infinitum.

This holds true especially for this study, but ultimately also for philology in general. ${ }^{23}$ Literary studies and partly also linguistics not only continually make implicit - and occasionally explicit - eternity-assertions toward characters and texts; they also do this in a manner that, to some degree, makes those assertions come true. This basic problem of a 'self-fulfilling prophecy' is only

21 It is not an accident that the auto-referential, auto-reflexive passage at the end of the Rosetta Stone's text was a decisive point of departure for the deciphering of the hieroglyphs! (cf. Doblhofer 200o, S. 56).

22 Cf. chapter 2.2. of the monograph's outlook.

23 See also Markus Rothhaar's outlook at the end of his essay on the antinomy of endlessness in Kant and Hegel, Rothhaar 2018, pp. 167-8. 
exacerbated - as has been shown in the historical chapters of the main part due to the fact that modern disciplines of philology (which, to some extent, can be traced back to the so-called Renaissance $\left.{ }^{24}\right)^{25}$ have emerged in the 18th century, of all things, in a context in which can be observed an accentuation of eternity-assertions and eternity-attributions of characters. Furthermore: Much points to the possibility that modern disciplines of philology originated from precisely that accentuation to which they have at the same time substantially contributed.

The best illustration of this, as has been shown, is Herder's essay on Shakespeare, which is seen in the German language area, of all things, as the beginning of modern historical literary studies - a similar observation may even be made for Wilhelm von Humboldt (who was inspired by Schiller's Wallenstein) and his influence on the nascent discipline of linguistics. ${ }^{26}$

These observations may ultimately also explain why there have been no systematic examinations of operations of the eternity-attribution of characters before the present study, since these operations constitute a 'blind spot' of those disciplines of whose fields of study such an examination ought to be a part. Every discipline that works with texts, especially those that fall within philology and history, must necessarily participate in the (as yet unwritten) history of the eternity-assertions and eternity-attributions of characters. ${ }^{27}$ It must also be assumed that it is precisely those disciplines which would write such a history. If, however, they refrained from procedures which intersect with operations of eternity-attribution, they would abolish themselves. Their 'only' option is to point, again and again and from varying perspectives, toward that 'blind spot'. In that sense, the present study also understands itself as a contribution, on the part of the disciplines of philology, to render more transparent their own eternity-assertions and -attributions - in the 'knowledge' that in such an undertaking is again unavoidably contained another potentially endless movement.

24 The term 'Renaissance' too should ultimately be described as eternity-assertion. It is not an accident that the term was not coined until the 19th century.

25 Cf. for this and regarding an 'auratic relation to the sources' A. Assmann 1999, especially pp. 120-121 as well as Nate 2018.

26 Cf. the end of chapter III.1.2.1.

27 Cf. especially chapter 4 of the introduction. 